\title{
MANAGING STRESS DURING YOUR PRACTICUM/INTERNSHIP
}

\section{INTRODUCTION}

Among the various mental health disciplines, the counseling profession is unique in that it was conceived with a strength-oriented wellness approach (Gladding, 2009; Myers, Sweeney, \& Witmer, 2000; Witmer \& Granello, 2005). Such an approach promotes a healthy and balanced life not only for clients, but also for counselors themselves. The intention of this chapter is to assist you in maintaining a healthier, more balanced life as you proceed through practicum and internship. As a future counselor, it is essential that you maintain a healthy lifestyle during your professional years (and well beyond, of course). Healthier counselors will likely be better counselors and enjoy more productive years in the profession. Self-care is part of the American Counseling Association (ACA) Code of Ethics (2014) as a buffer against impairment (Standard C.2.g) as is monitoring our effectiveness (Standard C.2.d). From my own anecdotal observation over the years, having witnessed many counselors' poor and marginal self-care, it is likely that substandard self-care is the most violated standard in the code of ethics. So, as counselors assisting others in developing healthier lifestyles, it is essential we practice what we teach.

As graduate students in a counseling program, you will also meet counselors, psychologists, social workers, and other mental health professionals who do not practice what they teach regarding self-care. Unfortunately, there are far too many counselors and other mental health professionals who struggle with addictions, codependence, anger management issues, and dangerously inflated egos, and whose behavior you will not want to emulate. You are not expected to have perfect behavior, never get upset, or have a total lack of conflicts. You are expected to learn to manage the challenges of your practicum and internship (and, more significantly, the demands of your life!). As a young graduate student, I had much difficulty in managing the stress involved in working, meeting academic demands, and managing a challenging practicum and internship setting. I hope this chapter provides some insights into recognizing stressors that accompany counseling a struggling population of clients. Furthermore, it is worth mentioning that for some 
students, their supervisors and fellow graduate students may provide more stress than the population they counsel! Workplace conflicts, not lack of professional knowledge, are the primary reason people leave their jobs (Bolles, 2015).

\section{DEVELOPING AND MAINTAINING A HEALTHY AND MINDFUL LIFESTYLE}

There are many different pathways, plans, theories, approaches, books, journal articles, and other resources devoted to living a healthy and fulfilling life. The fact that so many authors, counselors, theologians, personal trainers, coaches, and such attempt to provide counseling, coaching, and information to manage stress and teach mindfulness, a balanced diet, exercise routine, and so forth, is indicative of just how stressful daily life has become in this postmodern age. As graduate students on a practicum or internship, you are no stranger to the challenges of external demands. The practicum or internship experience placed atop family responsibilities, a job, academic work, and financial demands can create great stress in your life (Remley \& Herlihy, 2016). The irony of life as a graduate student in counseling is that while you are working to assist your clients to live healthier, more fulfilling lives, the demands of graduate school and practicum/internship, combined with work and home front demands, can potentially derail your own sense of harmony and balance. Somehow you must learn to effectively address this contradiction and develop healthy coping mechanisms. While every professional likely preaches better than she or he practices, developing healthy routines is essential for good physical, mental, and emotional health.

In this chapter devoted to managing stress on the practicum and internship, I have created several exercises for the purposes of self-reflection. Self-reflection is a critical task not only for counselors, but also for anyone in any occupation or walk of life and is a process of examining oneself during times of difficulty or success. The ability to step back from an experience, however successful or disappointing, can be a key skill for personal success as a counselor. I entitle this first section of the chapter "Developing and Maintaining a Healthy and Mindful Lifestyle." It is important for me to acknowledge that I have likely not created anything new in addressing the issues of healthy lifestyle or "wellness," as it is often referred to in the counseling field (Myers et al., 2000). Also included are assessments on quality of life, burnout, and mindfulness. Regardless of how we decide to refer to managing stress, living a balanced life, and mindful living, we usually address the same common themes of how to live a fulfilling, meaningful, and healthy life. I also offer a list of additional resources at the end of this chapter for counseling students to consider.

One of the first topics to address is that of stress. Stress is simply an everyday fact of life for everyone. Stress is an external change to which we are required to adjust our lives. Generally, we think of stress as being negative, such as death of a loved one, unemployment, divorce, and other such challenges. But positive changes in our lives can also bring about stress as well. For example, getting married or partnered, moving across the country for a new job, buying a home, traveling overseas, making your first conference presentation, and, of course, entering graduate school are all exciting experiences, but they can also bring about new stressors that complicate our lives. 
We can experience stress from three different sources: the environment, somatic ways, and our thoughts (Davis, Eshelman, \& McKay, 2008). Environmental stressors might be conflicts in the workplace, harsh weather, pollution, overcrowding, impoverishment, and living in unsafe areas. Environmental stressors are the ones we commonly see played up in the media, such as the 2009 catastrophic oil leak off the coast of Louisiana, Hurricane Sandy in 2012, slums in major cities, the trauma brought about by natural disasters such as that of Hurricane Katrina in New Orleans, the tsunami in Sri Lanka, and the earthquake in Haiti a few years ago. Environmental concerns clearly illustrate the connection between harmony with the environment and a less stressful life, or the exact opposite. Other common forms of environmental stress might be difficulties with your spouse/partner, roommates, colleagues at the office, and so forth.

The second source of stress is somatic, or how your body interprets stress. High-paced work settings, poor diet, sleep disturbances, and addiction all stress the body. Our reactions to these external demands are influenced by a genetic "fightflight-freeze" response inherited from primitive ancestors who dealt daily with life and death issues. These genetic traits were passed on to the subsequent generations to assist people in their adaptation to environmental demands. Consequently, we all have as part of our physiological system the innate tendency to prepare the body to face the stressor or to flee from it. An adaptive example of "fighting" might be the coworker who requests to speak with the party with whom he or she is having conflicts. Unhealthy fighting is when the same coworker screams obscenities at the other party. Adaptive "fleeing" is when someone takes a temporary break from the stressful event (say an argument with his or her spouse), and then returns and asks to speak with the party with whom he or she is having the conflict. Unhealthy fleeing is when the hurt person says, "They don't bother me," when in fact the other person's nasty comments or disrespectful actions do in fact bother him or her. Denial is a type of "unhealthy" fleeing. The critical factor here is "healthy" fighting and fleeing. The freeze response may occur when the fearful party cannot think of another response and stays put in the face of, say, verbal abuse.

The third source of stress derives from our thoughts. How you interpret or label stressful events will, in great measure, determine how well you resolve stress (Ellis, 2001). One of the ways our assumptions can add to stress is when we mistakenly interpret messages. For example, interpreting your supervisor's grimace to mean he or she is upset with you will likely create stress. But verifying this assumption might clear up the misunderstanding. In the event your boss is upset with you but has not voiced displeasure, addressing the issue is a pathway of moving through the stress. Remember that your supervisor's facial expressions, for example, may or may not have anything to do with you. So, do not overly interpret messages, but certainly investigate them.

\section{Effects of Stress}

Stress is difficult to define in a precise manner because it is a highly subjective phenomenon that differs for each of us. Experiences that are stressful for some are pleasurable for others. For example, some people actually look forward to swimming with sharks (namely, my spouse-but reef and nurse sharks, not Great 
Whites!), whereas others (myself) are terrified at the prospect. We respond to stress in different ways: some people eat less when stressed, others overeat, some turn pale whereas others blush, some use healthy coping skills such as exercise and talking with friends, and others self-medicate with alcohol and other drugs. Here are some common signs of stress:

- Frequent headaches

- Disturbed sleep

- Trembling of limbs

- Neck ache, back pain, muscle spasms

- Dizziness

- Sweating

- Frequent colds

- Stomach pain

- Constipation or diarrhea

- Hyperventilation

- Frequent urination

- Decreased sexual desire

- Excessive worry or anxiety

- Increased anger or frustration

- Decreased or increased appetite

- Depression or mood swings

- Difficulty concentrating

- Feeling overwhelmed

- Feelings of worthlessness

- Suicidal thoughts

- Social withdrawal

- Excessive defensiveness

- Reduced work efficiency

- Constant fatigue

- Feeling less hopeful

- Elevated blood pressure and heart rate

(adapted from the American Institute of Stress, n.d.).

\section{Tips for Managing Stress}

Because stress is a reality in daily life, you cannot eliminate it. You can, however, manage the stress that comes into your life. The following are several tips for managing stress. 


\section{Tip \#1: Recognize Stress and Deal With It Accordingly}

- Learn to say "no." This may take some practice. Know your limits and stay within them.

- Limit time with people you find stressful to be around. Conversely, maximize your time with people you find affirming and supportive.

- Take a break from stressors. If traffic causes you unmanageable stress, take a different route or use alternative forms of transportation if possible (e.g., carpool, mass transit, cycling). If the evening news stresses you, take occasional breaks from reading the paper, online news, or watching TV.

- Refrain from overly discussing upsetting topics (there is a time and place for such discussions, of course, just not too often). If discussing politics, religion, sex, or even sports causes you too much conflict, perhaps refrain from discussing them, at least with select people. If people try and engage you in arguments over these topics, simply inform them, "I don't discuss these topics."

- Prioritize your schedule. Make "to do" lists in order of importance. If there are unnecessary tasks, move them to the bottom of the list or eliminate them.

\section{Tip \#2: Be Proactive}

- Find constructive ways to express your feelings instead of suppressing them. Practice expressing your feelings with a trustworthy friend and solicit feedback from that friend. This way you will be more prepared to do so on your practicum/internship.

- Learn to be assertive. There is more on assertiveness later in the chapter.

- Manage time effectively. Poor time management skills will lead to additional stress. Prioritize your workload and this will help reduce your stress level.

- Be willing to compromise in conflicts. Do not make all the compromises, but make the ones you can.

\section{Tip \#3: Reframing Problems}

Reframing is a basic counseling technique. Here are some examples of how you might use reframing:

- Reframe personal conflicts as "growth opportunities" and seek to resolve them.

- Be realistic and let go of perfectionism. You are going to make mistakes on your practicum/internship. Make them and learn from them. Ask your supervisor for advice. Join the "recovering perfectionist" (RP) movement!

- Step back from a stress situation and ask: "How big an issue will this be in 6 months or a year?"

- On a regular basis, take time to reflect on the successes and blessings in your life. Challenging periods in life have a way of obliterating personal successes. So, take stock of your successes. 


\section{Tip \#4: Accept What You Cannot Change and Change What You Can}

- You cannot control other people. So, focus on how you react to their behavior and strategize more effective ways to deal with challenging people. A potentially more effective approach is focusing more on your goal as opposed to people's behavior. Remember that you cannot control another person's behavior, but you can manage your own.

- Get support. Discussing concerns with close friends can be very helpful. For one thing, you realize you are not alone; also, sharing a concern may provide an outside perspective you might find useful.

- Forgiveness. No one is perfect and, with rare exception, other people are not out to make our lives miserable. Learning to forgive perceived slights can free you from negative energy. If you have trouble with forgiving others, counseling may be a viable option for you. Forgiveness often is more for the forgiver than the perceived transgressor.

- Self-reflection. What do I need to change about myself? You might ask a few trusted friends to help you with this. Do they see areas you could improve on? How could you improve on these areas? What would self-improvement look like?

\section{Assessing and Preventing Compassion Fatigue and Burnout}

Compassionate fatigue and burnout are serious risks for counselors and counselors in training. Compassion fatigue represents frustration, feeling low energy, negative thoughts, workplace and home conflicts, and most symptoms of burnout (Stamm, 2005). Burnout is a longer term and more serious problem. Burnout may be described as a state of physical, mental, and emotional exhaustion brought about by long-term stress (Carter, 2013). Potential warning signs of burnout might be (Carter, 2013):

- Chronic fatigue: A sense of never feeling rested during the workday or weekends.

- Insomnia: Stress impacts sleep quality. You may experience difficulty falling or staying asleep.

- Impaired concentration: Feeling overwhelmed compromises your ability to remember basic details you typically recall with little difficulty.

- Physical symptoms: These may include shortness of breath, chest pain, gastrointestinal problems, dizziness, and headache. Naturally, all these should be assessed by a medical professional.

- Increased illness: Because your immune system is compromised, you may become more susceptible to cold and the flu.

- Loss of appetite: Food may no longer be appealing.

- Anxiety: Your anxiety may increase as you move from compassion fatigue to burnout. Panic attacks are a possibility. 
- Depression: You likely will feel sad initially, increasing in severity to ongoing depression. If sadness persists longer than a few days, seek professional help.

- Anger: As stress increases, momentary irritability may turn into angry outbursts.

\section{The Professional Quality-of-Life Scale}

The Professional Quality-of-Life Scale (ProQOL; Stamm, 2005) is the current version of the former Compassion Fatigue Test (Figley, 1995). Stamm (2005) modified the ProQOL to strengthen its psychometric properties and due to a preference for the more positive name of professional quality of life. Essentially, he wanted the instrument to have more of a healthy assessment and instructional focus and utility. Stamm's redevelopment research was based on more than 1,000 participants and statistically modified to include stronger subscale items (Stamm, 2005). The ProQOL now consists of three subscales: Compassion Satisfaction, Burnout, and Secondary Trauma. The ProQOL is suggested as a means of assessing quality of life as well as potential risk for burnout. Burnout risk is assessed as low, average, or high. The same scoring differentiation and cut-off scores are also used for the Compassion Satisfaction and Secondary Trauma scales. The ProQOL is reprinted with the author's permission in Exhibit 8.1.

\section{A Healthy Assets Ledger}

To build on your wellness practice, consider the following reflective questions. These questions are for you to use for purposes of self-exploration regarding personal, professional, and spiritual growth. Your answers are best utilized as a means of assessing emotional-spiritual-occupational-social balance in your life.

\section{Reflective Questions to Consider}

- How well-developed and balanced are the personal, occupational, social, and spiritual (if appropriate) dimensions of your life?

- Who do you say you are? Also, how does who you say you are compare to how others appear to view you? Or, how great is the distance between who you really are and who you want to be? Be realistic, but be honest about this "divide."

- How does this self-view correlate with how significant people in your life view you (you may wish to discuss this with relevant people in your life)?

- What is your most fulfilling time of the week? Why? If you feel a lack of fulfillment during your week, how could you create more meaning in your life?

- How would you describe this stage of your life?

- What issues and/or challenges are creating difficulty for you?

- How could you begin to lessen or better manage these challenges?

- What are your key strengths?

- What skills, hobbies, interests, and talents do you possess? 


\section{Exhibit 8.1 Professional Quality-of-Life Scale}

\section{Professional Quality-of-Life Scale (ProQOL) \\ Compassion Satisfactions and Fatigue \\ (ProQOL) Version 5 (2009)}

When you [help] people you have direct contact with their lives. As you may have found, your compassion for those you [help] can affect you in positive and negative ways. Below are some questions about your experiences, both positive and negative, as a [helper]. Consider each of the following questions about you and your current work situation. Select the number that honestly reflects how frequently you experienced these things in the last 30 days.

\section{$1=$ Never $\quad 2=$ Rarely $\quad 3=$ Sometimes $\quad 4=$ Often $\quad 5=$ Very Often}

1. I am happy.

2. I am preoccupied with more than one person I [help].

3. I get satisfaction from being able to [help] people.

4. I feel connected to others.

5. I jump or am startled by unexpected sounds.

6. I feel invigorated after working with those I [help].

7. I find it difficult to separate my personal life from my life as a [helper].

8. I am not as productive at work because I am losing sleep over traumatic experiences of a person I [help].

9. I think that I might have been affected by the traumatic stress of those I [help].

10. I feel trapped by my job as a [helper].

11. Because of my [helping], I have felt "on edge" about various things.

12. I like my work as a [helper].

13. I feel depressed because of the traumatic experiences of the people I [help].

14. I feel as though I am experiencing the trauma of someone I have [helped].

15. I have beliefs that sustain me.

16. I am pleased with how I am able to keep up with [helping] techniques and protocols.

17. I am the person I always wanted to be.

18. My work makes me feel satisfied.

19. I feel worn out because of my work as a [helper].

20. I have happy thoughts and feelings about those I [help] and how I could help them.

21. I feel overwhelmed because my case [work] load seems endless.

22. I believe I can make a difference through my work.

23. I avoid certain activities or situations because they remind me of frightening experiences of the people I [help].

24. I am proud of what I can do to [help].

25. As a result of my [helping], I have intrusive, frightening thoughts.

26. I feel "bogged down" by the system.

27. I have thoughts that I am a "success" as a [helper].

28. I can't recall important parts of my work with trauma victims.

29. I am a very caring person.

30. I am happy that I chose to do this work. 
Exhibit 8.1 Professional Quality-of-Life Scale (continued)

What is my score and what does it mean?

In this section, you will score your test and then you can compare your score to the interpretation below.

Scoring

1. Be certain you responded to all items.

2. Go to items 1, 4, 15, 17, and 29 and reverse your score. For example, if you scored the item 1 , write a 5 beside it. We ask you to reverse these scores because we have learned that the test works better if you reverse these scores.

\begin{tabular}{|l|l|}
\hline You Wrote & Change to \\
\hline 1 & 5 \\
\hline 2 & 4 \\
\hline 3 & 3 \\
\hline 4 & 2 \\
\hline 5 & 1 \\
\hline
\end{tabular}

To find your score on Compassion Satisfaction, add your scores on questions 3, 6, 12, 16, 18, $20,22,24,27$, and 30.

\begin{tabular}{|l|l|l|}
\hline $\begin{array}{l}\text { The Sum of My Compassion } \\
\text { Satisfaction Question Was }\end{array}$ & So My Score Equals & My Level of Compassion \\
\hline 22 or less & 43 or less & Low \\
\hline Between 23 and 41 & Around 50 & Average \\
\hline 42 or more & 57 or more & High \\
\hline
\end{tabular}

To find your score on Burnout, add your scores on questions 1, 4, 8, 10, 15, 17, 19, 21, 26, and 29. Find your score in the table below.

\begin{tabular}{|l|l|l|}
\hline The Sum of My Burnout Questions & So My Score Equals & My Level of Compassion \\
\hline 22 or less & 43 or less & Low \\
\hline Between 23 and 41 & Around 50 & Average \\
\hline 42 or more & 57 or more & High \\
\hline
\end{tabular}




\section{Exhibit 8.1 Professional Quality-of-Life Scale (continued)}

To find your score on Secondary Traumatic Stress, add your scores on questions 2, 5, 7, 9, 11, $13,14,23,25,28$. Find your score in the table below.

\begin{tabular}{|l|l|l|}
\hline $\begin{array}{l}\text { The Sum of My Secondary } \\
\text { Traumatic Stress Questions }\end{array}$ & So My Score Equals & My Level of Compassion \\
\hline 22 or less & 43 or less & Low \\
\hline Between 23 and 41 & Around 50 & Average \\
\hline 42 or more & 57 or more & High \\
\hline
\end{tabular}

YOUR SCORES ON THE PROQOL: PROFESSIONAL QUALITY-OF-LIFE SCREENING

Based on your responses, your personal scores are below. If you have any concerns, you should discuss them with a physical or mental healthcare professional.

\section{Compassion Satisfaction}

Compassion satisfaction is about the pleasure you derive from being able to do your work well. For example, you may feel like it is a pleasure to help others through your work. You may feel positively about your colleagues or your ability to contribute to the work setting or even the greater good of society. Higher scores on this scale represent a greater satisfaction related to your ability to be an effective caregiver in your job.

The average score is 50 (SD 10; alpha scale reliability 0.88 ). About $25 \%$ of people score higher than 57 and about $25 \%$ of people score below 43 . If you are in the higher range, you probably derive a good deal of professional satisfaction from your position. If your scores are below 40, you may either find problems with your job, or there may be some other reason, for example, you might derive your satisfaction from activities other than your job.

\section{Burnout}

Most people have an intuitive idea of what burnout is. From the research perspective, burnout is one of the elements of compassion fatigue. It is associated with feelings of hopelessness and difficulties in dealing with work or in doing your job effectively. These negative feelings usually have a gradual onset. They can reflect the feeling that your efforts make no difference, or they can be associated with a very high workload or a nonsupportive work environment. Higher scores on this scale mean that you are at higher risk for burnout.

The average score on the burnout scale is 50 (SD 10; alpha scale reliability 0.75 ). About $25 \%$ of people score above 57 and about $25 \%$ of people score below 43 . If your score is below 18 , this probably reflects positive feelings about your ability to be effective in your work. If you score above 57, you may wish to think about what at work makes you feel like you are not effective in your position. Your score may reflect your mood; perhaps you were having a "bad day" or are in need of some time off. If the high score persists or if it is reflective of other worries, it may be a cause of concern. 


\title{
Exhibit 8.1 Professional Quality-of-Life Scale (continued)
}

\begin{abstract}
Secondary Traumatic Stress
The second component of Compassion Fatigue (CF) is secondary traumatic stress (STS). It is about your work-related, secondary exposure to extremely or traumatically stressful events. Developing problems due to exposure to others' trauma is somewhat rare but does happen to many people who care for those who have experienced extremely or traumatically stressful events. For example, you may repeatedly hear stories about the traumatic things that happen to other people, commonly called Vicarious Traumatization. You may see or provide treatment to people who have experienced horrific events. If your work puts you directly in the path of danger, due to your work as a soldier or civilian working in military medicine personnel, this is not secondary exposure; your exposure is primary. However, if you are exposed to others' traumatic events as a result of your work, such as providing care to casualties or for those in a military medical rehabilitation facility, this is secondary exposure. The symptoms of STS are usually rapid in onset and associated with a particular event. They may include being afraid, having difficulty sleeping, having images of the upsetting event pop into your mind, or avoiding things that remind you of the event.
\end{abstract}

The average score on the burnout scale is 50 (SD 10; alpha scale reliability 0.81 ). About $25 \%$ of people score above 57 and about $25 \%$ of people score below 43 . If your score is above 57 , you may want to take some time to think about what at work may be frightening to you or if there is some other reason for the elevated score. While higher scores do not mean that you do have a problem, they are an indication that you may want to examine how you feel about your work and your work environment. You may wish to discuss this with your supervisor, a colleague, or a healthcare professional.

Source: From Stamm, B. H. (2012). Professional Quality of Life: Compassion Satisfaction and Fatigue Version 5 (ProQOL). Retrieved from https://www.proqol.org/uploads/ProQOL_5_English_Self-Score_3-2012.pdf

- What areas of your life would you like to explore? (Note: This could apply to personal relationships, travel, continuing education, career, or anything you deem important.)

- In what ways are you dependent on others?

- In what ways are you self-reliant?

- What conflicts are inhibiting your personal growth and professional effectiveness?

- How could you take steps to resolve these conflicts?

\section{Regarding Major Successes and Failures in Your Life}

- When you consider your major successes, what has worked well and why? What did your major successes teach you?

- Regarding your failures, what seemed to go wrong and why? What did your failures teach you?

- What could you do differently next time either to build on success or to ensure you did not fail in the next opportunity? 
Exhibit 8.2 represents a self-monitoring system using scaling questions. This assessment technique provides a sense of where you are in the respective domains. The self-rating questions are intended to help provide a constructive method of self-care. This approach is not intended as a substitute to replace good personal, professional, and spiritual growth, but to serve and support wellness in these areas.

\section{Exhibit 8.2 Dimensions of a Healthy Lifestyle: Self-Monitoring System}

\section{Spirituality/Religious Life and/or Life Meaning \& Purpose}

My spiritual/religious life provides a sense of purpose and helps me address major life challenges.

(Note: An alternate phrasing for nonspiritual/nonreligious people might be: "My sense of life meaning/purpose provides fulfillment and helps me address the challenges in my life.")

\section{$\begin{array}{llllllllll}1 & 2 & 3 & 4 & 5 & 6 & 7 & 8 & 9 & 10\end{array}$}

( 1 = no help at all; $10=$ strongly helps)

If your score was less than 5 , how could you improve your situation?

Mindfulness in Life:

I am grounded in the present, and fully accept myself nonjudgmentally. I use meditation (or prayer), and daily gratitudes and affirmations.

\section{$\begin{array}{llllllllll}1 & 2 & 3 & 4 & 5 & 6 & 7 & 8 & 9 & 10\end{array}$}

\section{Personal Vision}

"I have a clear vision in my personal, spiritual, and professional life."

$$
\begin{array}{llllllllll}
1 & 2 & 3 & 4 & 5 & 6 & 7 & 8 & 9 & 10
\end{array}
$$

( 1 = No vision; $10=$ I have a clear vision $)$

If you do not have a clear personal, spiritual, or professional vision, how could you develop one? Visioning is a key component to success in all these areas.

\section{Self-Worth}

"I feel worthwhile as a human being and have a strong sense of self-acceptance. Although I am not perfect, I feel generally good about myself."

\section{$\begin{array}{llllllllll}1 & 2 & 3 & 4 & 5 & 6 & 7 & 8 & 9 & 10\end{array}$}

( 1 = I am worthless; $10=$ My self-worth is very strong $)$

If you are experiencing low self-esteem, how could you begin to feel better about yourself? What actions could you take to begin to feel more self-confident? 


\section{Exhibit 8.2 Dimensions of a Healthy Lifestyle: Self-Monitoring System (continued)}

\section{Goal Setting}

"I feel self-confident about setting and meeting goals and demands in my life."

$$
\begin{array}{llllllllll}
1 & 2 & 3 & 4 & 5 & 6 & 7 & 8 & 9 & 10
\end{array}
$$

$(1=\mid$ lack confidence in my ability to meet demands and the goals I set; $10=\mid$ feel very confident in setting, planning, and meeting goals and demands)

If you lack clear goals in your life, how could you begin to create some clear goals?

\section{Rational Thinking}

"I believe I perceive my life and life situations in a rational manner. I seldom engage in overly negative thinking."

$\begin{array}{llllllllll}1 & 2 & 3 & 4 & 5 & 6 & 7 & 8 & 9 & 10\end{array}$

( 1 = I frequently engage in irrational thinking; $10=I$ am very rational in my beliefs)

If you have rated yourself as frequently engaging in irrational beliefs (e.g., "I am a loser," "I am worthless," "No one could ever love me"), how could you begin to think in a more rational manner? (Or, if you are unsure as to whether your beliefs are rational, you might consider asking someone you trust for feedback.)

\section{Emotional Understanding and Regulation}

"I am in touch with my emotions and am able to express the full range of emotions appropriate to the situation. I also am not governed by my emotions."

\section{$\begin{array}{llllllllll}1 & 2 & 3 & 4 & 5 & 6 & 7 & 8 & 9 & 10\end{array}$}

( 1 = I am not able to regulate my emotions and often express emotions inappropriate to the situation; 10 = I am able to regulate my emotions and experience emotions appropriate to the situation)

If you find you are not experiencing an appropriate range of emotions, or you find you are too often ruled by your emotions, how could you begin to change this? Remember, you will have "negative" emotions, so the task is to regulate them appropriately.

\section{Resilience}

"I am a resilient person, and able to analyze, synthesize, and make a plan to deal with challenges and projects that come my way."

\section{$\begin{array}{llllllllll}1 & 2 & 3 & 4 & 5 & 6 & 7 & 8 & 9 & 10\end{array}$}

$(1=I$ do not feel resilient; $10=$ I am very confident in my resiliency)

If you do not feel resilient (or you are not as resilient as you would like) or do not have the ability to resolve difficulties in your life, what could you do to begin to develop more resilience? (Note: If you feel stuck on strategizing with this component, perhaps begin by making a list of ways you feel resilient. Or, ask someone who knows you well to list ways he or she sees you as being resilient.) 
Exhibit 8.2 Dimensions of a Healthy Lifestyle: Self-Monitoring System (continued)

\section{Sense of Humor}

"I possess a healthy, appropriate sense of humor that helps me deal with the stresses of life."

\section{$\begin{array}{llllllllll}1 & 2 & 3 & 4 & 5 & 6 & 7 & 8 & 9 & 10\end{array}$}

( 1 = I have no sense of humor; $10=$ I have a healthy sense of humor)

If you do not feel your sense of humor is either strongly developed, appropriate, or provides an effective release of stress, what could you change to improve the situation?

\section{Fitness or Recreation}

"I have a regular weekly fitness/recreational routine that helps me stay physically and emotionally fit."

\section{$\begin{array}{llllllllll}1 & 2 & 3 & 4 & 5 & 6 & 7 & 8 & 9 & 10\end{array}$}

( 1 = I have no activity routine; $10=$ I have an active physical/recreational routine)

If you do not have a regular weekly fitness routine, what could you do to change this? (Remember, you do not need to become a marathoner, competitive cyclist, swimmer, or dancer. It is simply about developing a regular routine of 20 minutes a day, at least 3 days a week.)

\section{Healthy Diet}

"I regularly eat a balanced diet, including healthy vegetables and fruits."

(Note: Healthy is not meant to imply you never eat unhealthy foods because that is not realistic. In fact, sometimes it is good for the psyche to eat ice cream, cookies, and so forth. Just do not do it too often. Rather, it is about eating unhealthy food in moderation.)

\section{$\begin{array}{llllllllll}1 & 2 & 3 & 4 & 5 & 6 & 7 & 8 & 9 & 10\end{array}$}

( 1 = My diet is unbalanced and unhealthy; $10=$ My diet is balanced and healthy)

If your diet is unhealthy (eating high-fat food, "junk" food, fast food too often), how could you begin to eat a healthier diet? (For in-depth help, you may wish to consult a dietician.)

\section{Mindful Living}

"I maintain a mindful lifestyle by not abusing alcohol or other drugs, by wearing a seat belt, having regular medical exams, and by refraining from high-risk activities (e.g., casual sex, binge drinking, binge eating, restricting food)."

\section{$\begin{array}{llllllllll}1 & 2 & 3 & 4 & 5 & 6 & 7 & 8 & 9 & 10\end{array}$}

( 1 = I do not live a healthy, mindful life; 10 = I maintain a healthy, mindful lifestyle)

If you find you are not living a healthy, mindful life, what steps could you take to change this? 


\section{Exhibit 8.2 Dimensions of a Healthy Lifestyle: Self-Monitoring System (continued)}

\section{Managing Stress and Anxiety}

"Through my diet, workout routine, friendships, and so forth, I have the ability to manage stress and anxiety. When I find I am unable to manage the stress and anxiety in my life, I check in with close friends and family or, if the need arises, I see a counselor."

\section{$\begin{array}{llllllllll}1 & 2 & 3 & 4 & 5 & 6 & 7 & 8 & 9 & 10\end{array}$}

( 1 = I am regularly unable to manage the stress and anxiety in my life; $10=I$ am able to manage the stress and anxiety in my life)

If you find you regularly have difficulty managing the stress and anxiety in your life, how could you begin to manage that stress and anxiety better?

\section{Sense of Self}

"I feel that my self-identity is strong and well developed."

$\begin{array}{llllllllll}1 & 2 & 3 & 4 & 5 & 6 & 7 & 8 & 9 & 10\end{array}$

( 1 = My sense of self is incongruent with who I am because I try too hard to be who others want me to be; $10=$ My sense of self is very congruent with who I am)

Some people struggle with their own identity for various reasons, such as enmeshment with family, codependence with a loved one, low self-esteem, and so forth. If you find you are struggling with an inability to develop your own identity, what are some options for exploration (options that would reduce your struggle or help you resolve your personal identity struggles)?

\section{Connection to Family or Culture}

"I feel a strong connection to my family or culture."

\section{$\begin{array}{llllllllll}1 & 2 & 3 & 4 & 5 & 6 & 7 & 8 & 9 & 10\end{array}$}

$(1=I$ feel no connection to my family or culture; $10=\mid$ feel a strong and healthy connection to my family and culture)

In the event you feel no connection to your family or culture, what would you say accounts for this? Also, how could you begin to make stronger connections to your family and culture?

\section{Career/Vocational Development}

"I feel a sense of satisfaction in the career I am pursuing" (e.g., mental health counselor, school counselor, rehabilitation counselor).

$$
\begin{array}{llllllllll}
1 & 2 & 3 & 4 & 5 & 6 & 7 & 8 & 9 & 10
\end{array}
$$

( 1 = No satisfaction; $10=$ Maximum satisfaction $)$

If your chosen career does not provide personal challenge and satisfaction for you, what steps could you take to create more fulfillment and satisfaction? (Or, if you are unemployed, how could your job search become more fulfilling? Or, how could this period of unemployment be more productive?) 
Exhibit 8.2 Dimensions of a Healthy Lifestyle: Self-Monitoring System (continued)

\section{Hobbies}

"My hobbies help me relax and provide a sense of enjoyment."

$$
\begin{array}{llllllllll}
1 & 2 & 3 & 4 & 5 & 6 & 7 & 8 & 9 & 10
\end{array}
$$

$(1=I$ have no hobbies or they provide no sense of enjoyment or relaxation; $10=$ My hobbies are a pure joy)

If you lack hobbies or outside interests from work, how could you create some fulfilling pursuits?

\section{Social Life}

"I have healthy relationships that provide me a sense of emotional connection and help make life more rewarding."

\section{$\begin{array}{llllllllll}1 & 2 & 3 & 4 & 5 & 6 & 7 & 8 & 9 & 10\end{array}$}

( 1 = I have no significant relationships, they are shallow, or provide little in the way of emotional connection; $10=$ I have healthy and fulfilling relationships and they are an important part of my life)

If you lack significant personal connections or your relationships do not provide you a sense of emotional connection, how could you begin to address this? (Or, how could you begin to create fulfilling relationships?)

\section{Intimacy}

"Intimacy, or love, is a central part of my life and my relationship with my spouse/partner provides the grounding, intimacy, and close connection I need." (Note: Intimacy could involve sexual intimacy or even a close, nonsexual relationship.)

\section{$\begin{array}{llllllllll}1 & 2 & 3 & 4 & 5 & 6 & 7 & 8 & 9 & 10\end{array}$}

( 1 = Intimacy is largely absent from my life; $10=$ Intimacy is a large part of my life and provides me with great satisfaction)

If intimacy seems absent from your life, or seems unhealthy or unfulfilling, what do you need to do to change this situation?

\section{Questions Regarding Self-Care}

Regarding these dimensions, which appear to be strongest? Weakest? How could you improve your strengths and build upon your weak areas? What action could you take to improve your self-care? What supports do you need to create a healthier lifestyle? If you are unsure how to create a healthy self-care lifestyle, who could you ask for help (your doctor, counselor, a nutritionist, your spiritual leader, family member, friend, etc.)? 


\section{Additional Considerations for Managing Stress}

\section{Setting Limits With Others}

- Do you have difficulty saying "no" to other people? If you do, how could you begin to say "no" when you know doing so is necessary? What makes setting limits difficult for you? Guilt? Fear? Something else? How could you begin to practice setting limits with others? For example, saying "no" when you mean no?

- What healthy risks can you undertake to enhance your personal and professional growth?

- When you think about the type of people who cause you stress, what is it that they do that is stressful for you? Okay, now that you have identified what is stressful about their behavior, how could you manage your stress level around them?

\section{Developing Connections}

- Would you want to make friends with someone like yourself? Why or why not? If "no," what might you wish to change?

- If you feel isolated, how could you begin to develop meaningful relationships?

- If you are in a marriage or partnership and you are not feeling fulfilled, how could you begin to create a greater sense of fulfillment in that relationship?

- If you are not in a relationship and would like to be, how could you begin to create such a relationship? (Or, what qualities would you like in a partner?)

- Recall a difficult period in your life. How did you navigate your way through this time?

- How do you go about creating meaning in your life?

- Make a list of at least five skills you already possess that you can use to keep yourself well and fit.

\section{Work and Career}

- Are you pursuing the career you truly belong in? Why or why not?

- Why did you choose to pursue counseling as a career? How happy are you thus far?

- What is your dream job or dream career? (Describe in some detail: title, location, etc.)

- How can you begin to create your dream job? What steps are necessary?

- Setting goals is important for success. What are your major goals for the next 5 years?

- In what ways have you changed since entering your graduate counseling program? 


\section{Mentoring}

- Who are some people who have inspired you? Note: They need not necessarily be people you have met. For example, many have been inspired by the likes of Martin Luther King, Jr., Mahatma Gandhi, Mother Teresa, Dalai Lama, Stephen Hawking, and so forth, even though they have never met these people.

- Name five people and state how they have inspired you.

- Who are some people who share your hobbies and interests?

- Cite some organizations you are actively involved in.

- List some people who share your spiritual beliefs (or who share your personal values ).

\section{The Importance of Meaning and Purpose in Life}

Meaning in life is a concept of central importance to the human condition and has been studied across numerous disciplines (Schulenberg, Starck, \& Buchanan, 2011; Wong, 2012a, 2012b). Meaning in life has been a focal point of interest to theologians and philosophers for centuries, and more recently, the issue has become influential in the rapidly growing positive psychology movement (Schulenberg et al., 2011; Seligman, 2002; Sharma, Marin, Koenig, et al., 2017; Wong, 2012a). Meaning in life is positively correlated with happiness, well-being, resilience, coping skills, hope, self-esteem, and empowerment and inversely correlated with depression, post-traumatic stress disorder (PTSD), addiction, anxiety, and suicidality (Duffy \& Boque-Bogden, 2010; Seligman, 2002; Wong, 2012a). People who perceive their lives as having meaning are more likely to be happier, healthier, less depressed, and less anxious. "The presence of meaning is an excellent marker of the good life" (Peterson \& Park, 2012, p. 292).

While life meaning seems an important issue, the term is amorphous and often misunderstood (Heintzelman \& King, 2014). A perusal of the bestseller list, not to mention numerous workshops offered, suggests that the public is intensely interested in developing increased life meaning. While targeted as a necessity to emotional health, life meaning may be increasingly rare in a secularized society (Frankl, 1997; Wong, 2012a, 2012b). Thus, there is a dynamic tension between the hypothesis regarding the importance of meaning in life and research, suggesting many people lack appropriate life meaning. Given the dynamic nature of a fast-paced, western world, and the well-documented angst regarding 21st century college and graduate students' mental health needs (Much \& Swanson, 2010), meaning and purpose in life likely are critical necessities for emotional balance and well-being.

The Meaning in Life Questionnaire (MLQ) is a 10-item test assessing two dimensions of meaning in life on a 7-point scale from "Absolutely True" to "Absolutely Untrue" (Steger, Frazier, Oishi, \& Kaler, 2006). The "Presence of Meaning" subscale measures how the level of meaning in respondents' lives and the "Search for Meaning" subscale assesses respondents' level of motivation to find or deepen life meaning. The MLQ has demonstrated validity and reliability in research on clinical and nonclinical populations (Schulenberg et al., 2011). 


\section{CONFLICT MANAGEMENT SKILLS}

A big part of health and wellness involves managing conflict (Weinhold \& Weinhold, 2009). As a future counselor, you will have many opportunities to help clients and fellow students identify, address, and manage conflict. Conflict between people is actually a very natural occurrence; yet, many people find conflict to be traumatic and stressful. Conflict need not necessarily be traumatic, however, and if well managed and addressed, it may provide the foundation for personal growth. The critical factor regarding conflict is that we acknowledge it and then strategize on how to resolve it.

The first step in managing conflict is to admit that it exists. Because counseling can be demanding and stressful work, it is likely that you will have ample opportunities to work on developing competence in dealing with conflict. I have listed common assumptions about conflict, and then a reframed response to these assumptions.

Assumption 1: "All conflict is bad and should be avoided."

Reframed response: Conflict is not necessarily "bad." Acknowledging and addressing conflict can be liberating and improve self-confidence.

Assumption 2: "Conflict is awful and terrible."

Reframed response: Conflict is neither "awful" nor "terrible," although refusing to admit or address it can result in poor health. The trick is learning to manage conflict. This requires revising your self-talk, monitoring your blood pressure, and good emotional regulation (i.e., do not speak out of anger).

Assumption 3: "I simply can't deal with conflict."

Reframed response: Dealing with conflict is sometimes unpleasant for me. However, the more experienced I become at addressing conflicts, the more confident and effective I become at resolving them.

Assumption 4: "When I have conflicts they always 'blow up' into something unmanageable, so it's just better to ignore them."

Reframed response: Sometimes my attempts at conflict resolution go awry and tempers can escalate. However, in many, if not most cases, I am able to navigate conflict without causing further injury. Remember: Good emotional regulation, revised self-talk, and monitoring blood pressure.

Now, a critical factor beyond admitting the existence of conflicts is how we go about resolving them. Fortunately, people can improve their conflict resolution skills with practice. As a counselor operating from a cognitive framework, I believe conflict resolution is grounded in childhood experiences of observing and participating in family conflicts. Our parents or guardians consciously or unconsciously modeled styles of conflict resolution, which we internalized and then repeated in our conflicts with siblings and peers. Some families are more functional at addressing conflicts; children raised in more functional homes will have an early advantage at conflict resolution. Children raised in less functional, dysfunctional, abusive, or neglectful homes will likely have more struggles in 
resolving conflicts as conflicts may have been denied or blown up into destructive aggression.

\section{Conflict Resolution Styles}

- The Denier: "Conflict? What conflict?" "Everything's just perfect."

- The Minimizer: "It's not anything to worry about." "No big deal."

- The Overly Responsible Type: "It's all my fault."

- The Avoider: "It's better to avoid conflict regardless of the cost."

- The Aggressor: "You have to get in people's faces! That's how you resolve conflicts."

- The Mindful Type: “OK, there is a conflict. What steps can I take to resolve it?"

Examine the types and think about which type best fits how you generally behave when faced with conflicts. No one will always choose only one type, but decide which of the conflict resolution styles most frequently describes you. Now, think about which of these styles you would prefer.

The following questions are aimed to focus your awareness on your current conflict resolution style and how you would like to modify it.

- Which of the mentioned conflict resolution style types would usually describe the manner in which I deal with conflicts?

- What do I fear about conflicts? (or, What is the worst thing that could happen regarding conflicts?)

- What types of conflict situations do I find most challenging?

- Who were my role models in learning how to address conflicts?

- What are my strengths in resolving conflicts?

- How effective is my style of conflict resolution?

- In what situations does my approach to resolving conflicts work?

- In what situations does my approach to resolving conflicts seem ineffective?

- What would I want to change about my style of conflict resolution?

- How could I begin to change my approach to conflict resolution?

- What is one small change I can make that will help me address conflicts more effectively?

- My biggest challenge in improving my conflict resolution skills is . . .

- Think of someone who seems effective in resolving conflicts. What conflict resolution skills does he or she possess?

- What, in my professional training and background, assists me in resolving conflicts?

- What types of conflict resolution work do I see myself performing in the future? 
Box 8.1 Conflict Resolution Practice for the Counseling Practicum/Internship

\section{CONFLICT SCENARIO ONE}

You have just commenced your practicum. You get along very well with most of the staff and fellow graduate practicum students. However, after a few weeks, you discover another practicum student seems to be constantly belittling you (e.g., "You haven't learned much about counseling, have you?" "Your approach to counseling is all wrong."). You decide not to address the issue, hoping it will just resolve itself. Then, one of the other graduate students informs you the student in question is bad mouthing you to the others.

How would you resolve this apparent conflict? What actions would be most constructive? What would healthy resolution look like? Now, if possible, role-play the scenario out with a classmate or friend. The more you practice resolving conflicts, the more skilled you will become at resolving them. You cannot force the other person to act professionally and respectfully, but you can behave both ways.

\section{CONFLICT SCENARIO TWO}

You have completed practicum and are beginning internship at your placement. Your new supervisor seems very harsh with his criticism and is somewhat sarcastic during supervision sessions, making comments such as "This is subpar work!" and "I can't believe your last supervisor saw your work as worthy of passing practicum." Your supervisor also discloses he really did not want to supervise you, but was forced to do so by the director of clinical services. Intimidated and discouraged, you soon discover yourself avoiding him whenever you can; as weekly supervision arrives, your stomach is upset and you feel very anxious. You realize this is an unhealthy situation and you would like to switch supervisors, but worry the answer will be "no" and that your supervisor may hold your actions against you. What steps might you make to deal with this conflict? Who might be supports for you in this challenging situation?

- What types of conflict resolution roles would be inconsistent with my future practice as a counselor?

- How would being skilled in conflict resolution assist me in becoming an effective counselor?

Box 8.1 presents conflict scenarios designed to help you think about your own approach to conflict management.

\section{THE COUNSELING STUDENT AS CLIENT}

Counseling work can certainly be very stressful, as clients bring in difficulties of their own and there may be job conflicts with coworkers. As a graduate student in a counseling program, you have the added complication of coursework, along with seeing clients, balancing a home life, and numerous additional demands. Many counseling programs now mandate a few counseling sessions for their students. Counselors who have had the experience of being clients themselves have 
a more complete understanding of the therapeutic process (Norcross, Strausser, \& Faltus, 1988). Putting yourself in the vulnerable position as a client also provides you the opportunity of experiencing the "other side" of the therapeutic experience and likely can help you develop more empathy for clients and their struggles.

I can state from experience that many counselors and other mental health professionals sometimes are reluctant to seek counseling services for themselves, out of their fear or arrogance, or simply being unaware of the extent of their personal issues. Self-care is a critical component of effective function for counselors and an issue addressed in the ACA Code of Ethics (2014, Standard C.2.g). As a future professional counselor, graduate school is the optimal time to begin addressing your own mental health to ensure whatever personal concerns you have do not impact your counseling work. This is not to say you must be perfect to be a counselor; every counselor, no matter how successful and well-adjusted, has some personal "baggage." Most importantly, understand your issues and work to improve on them. After all, such is the nature of counseling work.

If you decide that entering personal counseling would be a good idea, you should be aware that many counselors, psychologists, social workers, and other mental health professionals have already reached similar conclusions. Mahoney (1997) reported that $87 \%$ of mental health professionals surveyed admitted they had entered personal counseling at some point in their careers. Personal counseling was rated by mental health professionals as second to practical experience as the most important influence in their professional lives. A study of 500 counselors and psychologists revealed that $93 \%$ rated the experience from mildly positive to very positive (Baird, Carey, \& Giakovmis, 1992). Other notable counseling professionals such as Sam Gladding (2009) have posited personal counseling as a critical growth experience for counselor development. In fact, in the event that it has been a lengthy period of time since a counselor was a client, it is likely a good idea to seek counseling services as a mental health "checkup" and to better empathize with the clients being served.

Pope and Tabachnick (1994) conducted a study of more than 800 psychologists, in which $84 \%$ admitted to having been in personal therapy. The most often cited reasons for mental health professionals to seek counseling were (in descending order) depression; divorce or relationship difficulty; struggles with self-esteem; anxiety, or career, work, or study concerns; family of origin issues; loss; and stress (Pope \& Tabachnick, 1994). Among those surveyed, 85\% described the therapeutic experience as very or exceptionally helpful. What these and other studies suggest is that personal counseling can be very important for our own emotional health and personal growth. Furthermore, personal counseling helps counselors and other therapists remain healthy and in doing so they likely are more effective at providing counseling. Furthermore, many counseling professionals have chosen to become helping professionals because of positive, life-transforming experiences through their own personal counseling (perhaps even readers of this text).

In addition to counseling, support groups can serve an important role for counselors and certainly for graduate students. I am not aware of counseling programs that require student participation in support groups, but it is a worthwhile 
concept, particularly given the stressful nature of graduate study, practicum and internship demands, and because the Council for Accreditation of Counseling and Related Educational Programs (CACREP, 2016) standards essentially mandate training reflective counseling professionals. In my own graduate counseling program, we were required to participate in an intensive growth experience for 3 days. I was both a participant as a master's degree student and later a group facilitator as a doctoral student. My experience in both groups was educational and very informative regarding the power of the group experience on individuals. However, my belief is that an ongoing support group would be more impactful regarding students' personal growth and development.

\section{FINAL SUGGESTIONS FOR SELF-CARE}

Kenneth Blanchard, famous for the best-selling book The One Minute Manager, cowrote a follow-up book titled The One Minute Manager Gets Fit in 1986. He was motivated to write this book after realizing that he was so consumed with chasing success that he forgot the most important thing: to keep his life in balance (Blanchard, Edington, \& Blanchard, 1986). He ate junk food, failed to work out, his weight ballooned, and his blood pressure rose to dangerously high levels (Blanchard et al., 1986). In the book, he listed the following as a means of assessing fitness level:

- I love my job. (Most of the time.)

- I use safety precautions like wearing a seat belt in moving vehicles.

- I am within 5 pounds of my ideal weight.

- I know three methods to reduce stress that do not include the use of drugs or alcohol.

- I do not smoke.

- I sleep 6 to 8 hours each night and wake up refreshed.

- I engage in regular physical activity at least three times per week. (Including sustained physical exertion for 20 to 30 minutes, e.g., walking briskly, running, swimming, biking, plus strength and flexibility activities.)

- I have seven or fewer alcoholic drinks a week.

- I know my blood pressure.

- I follow sensible eating habits. (Eat breakfast every day; limit salt, sugar, and fats like butter, eggs, whole milk, breakfast meats, cheese, and red meat; and eat adequate fiber and few snacks.)

- I have a good social support system.

- I maintain a positive mental attitude (p. 36).

The list contains many common-sense items, yet it is clear that many people, including some graduate students and professional counselors, struggle with 
many of them. Regular medical checkups on an annual basis are also highly recommended. Graduate students who lack health insurance should check with their student health service as medical care is usually subsidized by student fees and is significantly less expensive than off-campus providers. Furthermore, as previously noted, good self-care is an ethical construct (Standard C.2.g); graduate counseling students would be wise to begin working on self-care development. Professionals at college and university counseling centers, student health centers, and clergy are in a good position to assist with this. Social support systems are critical for wellbeing as well. Students feeling isolated would be wise to check with a counselor or another of these aforementioned professionals. Support groups can be helpful as can getting involved in a club or organization in an interest area (e.g., running club, meditation group, hiking club, etc.).

\section{Assessing Your Stress}

Stress is a major component of health-related issues and conditions related to anxiety, depression, and a number of somatic problems (Burns, 1993). The Perceived Stress Scale-4 (Pss-4; Cohen, Kamarck, \& Mermelstein, 1983) is a brief test to assess your stress level (see Exhibit 8.3).

\section{Self-Care: Your Owner's Manual on Well-Being}

Self-care plans can provide a buffer against compassionate fatigue or burnout (Stamm, 2005). A sample self-care plan is provided in Exhibit 8.4 for the reader's consideration.

\section{Exhibit 8.3 Perceived Stress Scale-4 (PSS-4)}

Circle the number that best represents your stress level on each of the following questions:

1. In the last month, how often have you felt you were unable to control the important things in your life?

Never (0) Almost Never (1) Sometimes (2) Fairly Often (3) Very Often (4)

2. In the last month, how often have you felt confident about your ability to handle your problems?

Never (0) Almost Never (1) Sometimes (2) Fairly Often (3) Very Often (4)

3 . In the last month, how often have you felt that things were going your way?

Never (0) Almost Never (1) Sometimes (2) Fairly Often (3) Very Often (4)

4. In the past month, how often have you felt difficulties were piling up so high that you could not resolve them?

Never (0) Almost Never (1) Sometimes (2) Fairly Often (3) Very Often (4) 


\title{
Exhibit 8.3 Perceived Stress Scale-4 (PSS-4) (continued)
}

\author{
Scoring for the Perceived Stress Scale 4 (PSS-4) \\ Questions 1 \& 4 \\ Questions 2 \& 3 \\ $0=$ Never \\ $4=$ Never \\ $1=$ Almost Never \\ $3=$ Almost Never \\ $2=$ Sometimes \\ $2=$ Sometimes \\ $3=$ Fairly Often \\ $1=$ Fairly Often \\ $4=$ Very Often \\ $0=$ Very Often \\ Lowest Score: 0 \\ Highest Score: 16 \\ Higher scores are correlated to feeling more stressed. \\ Source: From Cohen, S., Kamarck, T., \& Mermelstein, R. (1983). A global measure of perceived stress. \\ Journal of Health and Social Behavior, 24, 385-396. doi:10.2307/2136404
}

\section{Exhibit 8.4 A Sample Self-Care Plan for Counselors and Counselors in Training}

Secondary trauma, compassion fatigue, and burnout are serious concerns for any counselor or counselor in training. These may be avoided, however, provided a counselor has a good selfcare plan. For a viable self-care plan, I recommend a minimum of seven dimensions: physical, emotional, cognitive, social, financial, spiritual care, and creative self-care. Naturally, there will be many variations to self-care plans, even within the seven dimensions I have recommended. The following is one example of how to construct a self-care plan.

Author's Note: An active self-care plan is very helpful in managing stress counselors and counselors in the training phase. A self-care plan, though helpful, is no guarantee against compassionate fatigue or burnout.

\section{Physical Self-Care Dimension}

The activities I do regularly to care for my body in healthy ways. Healthy examples may include regular exercise (e.g., jogging, yoga, weight training, etc.), a balanced diet, abstinence from tobacco and alcohol (or moderate consumption), regular sleep, and annual physicals. In the space provided, identify three activities you regularly engage in (or plan to engage in) to take care of your physical self:
A.
B.
C.

\section{Emotional Self-Care Dimension}

The healthy activities I engage in to care for my emotional self. Examples may include: daily or weekly journaling, counseling (if necessary), joining a support group, practicing healthy 


\section{Exhibit 8.4 A Sample Self-Care Plan for Counselors and Counselors in Training (continued)}

self-talk and positive affirmations, and so on. In the space provided, list three activities you currently do or plan to engage in to care for your emotional self:
A.
B.

C.

3. Cognitive Self-Care Dimension

Cognitive self-care includes activities you undertake to engage your mind in a creative task. Cognitive self-care activities might include reading for pleasure, playing scrabble, completing crossword puzzles, continuing education for your career (or future career), taking classes for enjoyment, learning a new skill, and so on. In the space provided, list three cognitive self-care examples you regularly engage in (or will engage in):
A.
B.
C.

\section{Social Self-Care Dimension}

As humans are social creatures, it is important to maintain healthy relationships. Examples could include socializing with friends, family, and colleagues, joining clubs and organizations, going to plats or movies with a spouse/partner/friend, and so on. In the space provided, identify three social self-care activities you currently engage in (or will engage in) to care for your social self:
A.
B.
C.

\section{Financial Self-Care Dimension}

Financial self-care includes how I spend and save money and make responsible financial decisions. (I realize this can be challenging as a graduate student on a fixed budget.) Examples include balancing your checking account, maintaining a healthy savings account, speaking with a financial planner regarding investments or future investments, attending a financial planning class, or purchasing some of your clothes at Goodwill, the Salvation Army, and so on. In the space provided, identify three activities that you currently do or are planning to do for financial self-care:
A.
B.
C.

\section{Spiritual and Mindfulness Self-Care Dimension}

Most people are spiritual beings in some manner. This may include membership in a faith community (e.g., church, mosque, temple, etc.), 12-step community, regular individual or group meditation, mindfulness practice, and so on. Author's note: A person may have no spiritual inclination but likely finds ways to incorporate meaning and purpose into his or her life. If you are not spiritually inclined, consider how meaning and purpose manifest in your life. In the space provided, identify three spiritual/meaning activities you regularly engage in (or plan to engage in):
A.
B.
C. 


\section{Exhibit 8.4 A Sample Self-Care Plan for Counselors and Counselors in Training (continued)}

\section{Creative Self-Care Dimension}

Everyone is a creative person. Creativity does not require world-class talent and fame, but simple ways whereby you regularly engage in such pursuits. Creative expressions may include singing solo or in a choir; playing a musical instrument; writing poetry, prose, or music; creating any work of art; performing in community theatre; and so on. In the space provided, cite three creative activities you regularly engage in (or will engage in):

A.

B.

C.

\section{CONCLUSION}

The practicum and internship experience is intense and can be a very demanding and, occasionally, stressful time for a graduate student. The good news is that survival rates are very high and it is likely that you will manage stressful times quite well. You should expect occasional times, however, when you feel overwhelmed or "stressed out." These times, though unpleasant, also provide some of the greatest opportunities. You will get to practice the same stress management techniques and skills you have been teaching your clients. This is where self-reflection, reframing, meditation, prayer, exercise, friendships, and so forth, are so valuable and rewarding. Be aware of your stress and anxiety levels and monitor them closely so that you remain physically and emotionally healthy. A burned-out counselor-one who tries to be everything to everyone-fails to set limits, lacks assertiveness, eats a poor diet, and has no significant friendships and is likely to be of limited value to his or her clients. So, understand yourself and your emotional and physical limitations and work to stay within them. Use assessments such as the ones in this chapter to assess stress levels, a healthy lifestyle, meaning in life, and others to develop a self-care plan that is realistic and works for you.

\section{RECOMMENDED RESOURCES}

\section{Resources for Managing Stress}

Brinkman, R., \& Kirschner, R. (2002). Dealing with people you can't stand: How to bring out the best in people at their worst. New York, NY: McGraw-Hill.

Greenberger, D., \& Padesky, C. A. (1995). Mind over mood: A cognitive therapy treatment manual for clients. New York, NY: Guilford Press.

Myers, J. E., \& Sweeney, T. J. (Eds.) (2005). Counseling for wellness: Theory, research, and practice. Alexandria, VA: American Counseling Association.

Williams, M. B., \& Poijula, S. (2000). The PTSD workbook: Simple effective techniques for overcoming traumatic stress symptoms. Oakland, CA: New Harbinger. 


\section{Resources for Conflict Resolution}

The following books are good resources for ideas, self-reflection, and skill building regarding conflict resolution:

Barsky, A. E. (2017). Conflict resolution for the helping professions (3rd ed.). Oxford, UK: Oxford University Press.

Fisher, R., \& Ury, W. (1981). Getting to yes: Negotiating agreement without giving in. New York, NY: Penguin Books.

\section{REFERENCES}

American Institute of Stress. (n. d.). 50 common signs and symptoms of stress. Retrieved from https:// www.stress.org/stress-effects\#effects

Baird, B. N., Carey, A., \& Giakovmis, H. (1992). Personal experience in psychotherapy: Differences in therapists' cognitions. Paper presented at the Western Psychological Association, Portland, OR.

Blanchard, K., Edington, D. W., \& Blanchard, M. (1986). The one minute manager gets fit. New York, NY: Quill.

Bolles, R. N. (2015). What color is your parachute? A practical manual for job-hunters and career-changers. Berkeley, CA: Ten Speed Press.

Burns, D. D. (1993). Ten days to self-esteem. New York, NY: Harper.

Carter, S. B. (2013, November 26). The tell tale signs of burnout. . do you have them? Psychology Today. Retrieved from https://www.psychologytoday.com/us/blog/high-octane-women/201311/ the-tell-tale-signs-burnout-do-you-have-them

Cohen, S., Kamarck, T., \& Mermelstein, R. (1983). A global measure of perceived stress. Journal of Health and Social Behavior, 24, 385-396. doi:10.2307/2136404

Council for Accreditation of Counseling and Related Educational Programs. (2016). 2016 CACREP standards. Retrieved from https://www.cacrep.org/for-programs/2016-cacrep-standards

Davis, M., Eshelman, E. R., \& McKay, M. (2008). The relaxation and stress management workbook (6th ed.). Oakland, CA: New Harbinger.

Duffy, R. D., \& Raque-Bogdan, T. L. (2010). The motivation to serve others: Exploring relations to career development. Journal of Career Assessment, 18, 250-265. doi:10.1177/1069072710364791

Ellis, A. (2001). Overcoming destructive beliefs, feelings, and behaviors. Amherst, NY: Prometheus Books.

Figley, C. R. (1995). Compassion fatigue: Coping with secondary traumatic stress disorder in those who treat the traumatized. New York, NY: Brunner Mazel.

Frankl, V. E. (1997). Man's search for ultimate meaning. New York, NY: Plume.

Gladding, S. T. (2009). Counseling: A comprehensive profession (6th ed.). Upper Saddle River, NJ: Merrill/ Prentice Hall.

Heintzelman, S. I., \& King, L. A. (2014). Life is pretty meaningful. American Psychologist, 69, 561-574. doi:10.1037/a0035049

Mahoney, M. J. (1997). Psychotherapists' personal problems and self-care patterns. Professional psychology: Research and practice, 28, 14-16. doi:10.1037//0735-7028.28.1.14

Much, K., \& Swanson, A. L. (2010). Are college students really getting sicker? Journal of College Student Development, 24(2), 86-97. doi:10.1080/87568220903558570

Myers, J. E., Sweeney, T. J., \& Witmer, J. M. (2000). The Wheel of Wellness counseling for wellness: A holistic model for treatment planning. Journal of Counseling \& Development, 78(3), 251-266. doi:10.1002/j.1556-6676.2000.tb01906.x

Norcross, J. C., Strausser, D. J., \& Faltus, F. J. (1988). The therapist's therapist. American Journal of Psychotherapy, 42, 53-66. doi:10.1176/appi.psychotherapy.1988.42.1.53

Peterson, C., \& Park, N. (2012). Character strengths and the life of meaning. In P. T. Wong's (Ed.), The Human quest for meaning: Theories, research, and applications (2nd ed., pp. 277-295). New York, NY: Routledge.

Pope, K. S., \& Tabachnick, B. G. (1994). Therapists as patients: A national survey of psychologists' experiences, problems, and beliefs. Professional Psychology: Research and Practice, 25, 247-258. doi:10.1037/0735-7028.25.3.247

Remley, T. P., Jr., \& Herlihy, B. (2016). Ethical, legal and professional issues in counseling (5th ed.). Upper Saddle River, NJ: Pearson. 
Schulenberg, S. E., Strack, K. M., \& Buchanan, E. M. (2011). The Meaning in life questionnaire: Psychometric properties with individuals with severe mental illnesses in an inpatient setting. Journal of Clinical Psychology, 6, 1210-1219. doi:10.1002/jclp.20841

Seligman, M. E. P. (2002). Authentic happiness: Using the new positive psychology to realize your potential for lasting fulfillment. New York, NY: Free Press.

Sharma, V., Martin, D. B., Koenig, H. K., Feder, A., Iacoviello, B. M., Southwick, S. M., \& Pietzak, D. H. (2017). Religion, spirituality, and mental health of U.S. military veterans: Results from the national health and resilience in veterans study. Journal of Affective Disorders, 217(9), 197-204. doi:10.1016/jad.2017.03.071

Stamm, B. H. (2005). The ProQOL manual. Baltimore, MD: Sidran Press.

Stamm, B. H. (2012). Professional Quality of Life: Compassion Satisfaction and Fatigue Version 5 (ProQOL). Retrieved from https://www.proqol.org/uploads/ProQOL_5_English_Self-Score_3-2012.pdf

Steger, M. F., Frazier, P., Oishi, S., \& Kaler, M. (2006). The Meaning in Life Questionnaire: Assessing the presence of and search for meaning in life. Journal of Counseling Psychology, 53(1), 80-93. doi:10.1037/0022-0167.53.1.80

Weinhold, B. K., \& Weinhold, J. B. (2009). Conflict resolution: The partnership way (2nd ed.). Denver, CO: Love Publishing.

Witmer, J. M., \& Granello, P. F. (2005). Wellness in counselor education and supervision. In J. E. Myers \& T. J. Sweeney (Eds.), Counseling for wellness: Theory, research, and practice. Alexandria, VA: American Counseling Association.

Wong, P. T. P. (2012a). Introduction: A roadmap for meaningful research applications. In P. T. P. Wong (Ed.), The human quest for meaning: Theories, research, and applications (2nd ed., pp. xxix-xlvi). New York, NY: Taylor \& Francis.

Wong, P. T. P. (2012b). The meaning mindset: Measurement and implications. International Journal of Existential Psychology \& Psychotherapy, 4, 1-3. http://journal.existentialpsychology.org/index. $\mathrm{php} /$ ExPsy/article/view/181 